\title{
Practice and Experience of Light Chemical Equipment Course during Teaching Link
}

\author{
Heng Zhang ${ }^{1, a}$, Pengfei $\mathrm{Li}^{1, \mathrm{~b}}$, Tian Zhang ${ }^{1, \mathrm{c}}$, Hongkun Gao ${ }^{1, \mathrm{~d}}$ and Huixia Lan ${ }^{2, \mathrm{e} *}$ \\ ${ }^{1}$ College of Chemical Engineering, Qingdao University of Science \& Technology, Qingdao, \\ Shandong, China \\ ${ }^{2}$ College of Environment and Safety Engineering, Qingdao University of Science \& Technology, \\ Qingdao, Shandong, China \\ ahgzhang@sina.com, blpf619786@163.com, c1085989055@qq.com, dgaohongkun123@163.com, \\ "lanhuixia@163.com \\ *The corresponding author
}

Keywords: Education; Teaching effect; Reform in education; Light chemical; Teaching method

\begin{abstract}
In this paper, the light chemical equipment course during teaching link was analyzed and discussed. Four aspects include the selection of teaching content, correct thinking method and good working habits of students, the diversity of teaching methods and the reformation of teaching methods were analyzed and summarized. It was believed that the feedback was necessary for course construction, which could not only promote the overall level of the course, but also improve the teaching level of the teachers themselves.
\end{abstract}

\section{Introduction}

"Light chemical equipment" is a professional compulsory course for undergraduate students majoring in light chemical engineering, Qingdao University of Science \& Technology. It mainly includes a variety of specialized equipment in the light chemical industry. Through learning this course, students can be familiar with light industry project involved the types of equipment and the structure and working principle of typical equipment, with the purpose of promoting the students to master the basic knowledge of equipment selection, usage, management, maintenance and improvement.

The course construction of "light chemical equipment" is a systematic project, which involves all aspects of teaching materials, teaching methods and teaching conditions. At the same time, the curriculum construction is a dynamic process, which must be adapted to the progress of the research field and the technological progress. We always pay attention to the organic combination of these aspects in the compilation of teaching materials, the production of courseware and the classroom teaching process, and carried on the beneficial exploration. Then I will give you a detailed description of these questions which combined the practice of light chemical equipment course construction.

\section{Restructuring and Refining Teaching Content}

"Light chemical equipment" included four professional direction, pulp and papermaking engineering, dyeing and finishing engineering, leather engineering and fermentation engineering. In the broad sense, which relates to the daily life of chemical production can be attributed to the category of "Light chemical engineering". Therefore, the selection of teaching materials and teaching content, basically based on the following three aspects:

Firstly, it is based on the main content of traditional light chemical industry, including pulp and papermaking engineering, fermentation engineering, etc., which is held to all universities open this course. The second aspect is based on the discipline of our school, in our school, the fine chemical engineering is the predecessor of light chemical engineering, so we have traditional academic advantages, a lot of backbone teachers, complete system of laboratory and the practice base 
cooperated with enterprise. More importantly, we have a good reputation and visibility in the province and even the country's chemical and fine chemical industry. Therefore, for teaching and the course of teaching materials, fine chemical equipment also accounted for a lot of space and time, and it can be helpful for our school to play the advantages of traditional disciplines and students' employment. And the last one is based on the development of domestic and foreign light chemical industry, the different disciplines in the professional direction of teaching link for the use of time is different. For the pulp and papermaking engineering and fine chemical industry, we can explain it in detail; and for sugar engineering and leather engineering, which has slow development, employment prospects and bad channels direction, is only a general introduction [1].

The teaching materials and teaching contents into three aspects, which can stress the main points in the limited teaching time, so that students can grasp the development direction and trend of light chemical equipment in learning link, reduce their familiarity time with production technology, adapt to production site as soon as possible, combine knowledge with production.

\section{Constructing a Bridge between the Basic Theory and the Correct Thinking Method and Working Ability of Students}

After three years of basic and professional courses study, Light chemical engineering students just enter the course of learning in the first term of fourth years. The currently existing problems in the curriculum design is the training plan of the course focused on process engineering and despised on the basis of mechanical equipment, especially there is no open courses about engineering mechanics, mechanics of materials, measurement and interchangeability theory and material processing. In my survey on the course of teaching effectiveness questionnaire, when asked whether the students have any understanding of the machinery and equipment before studying this course, most students have no basic foundation, and in the equipment involved in the learning process is only a structural diagram on the textbook, In the process of learning can only rely on the imagination of its process operations and processes. In this way, the students are very difficult to learn a lot of the content about the structural design of the equipment and material strength checking calculation.

Therefore, I start from two aspects: first in teaching, not directly on the equipment, but focus on the basic components of the equipment such as containers, pipes, flanges, etc., and to supplementary explanation for the basic knowledge of Engineering Mechanics and equipment preparation process theory and common sense, and requires students to master the use of these knowledge, so in the back of the special equipment in the interpretation of the basic knowledge of the previous study, so that students can learn together, and then try to decompose the structure of many strange professional equipment, so as to draw inferences about other cases from one instance, for the future work in the design of equipment to provide the right way of thinking. Secondly, in the last part of the teaching content, arrange the practical knowledge of equipment installation, maintenance and maintenance, Enable students to obtain a comprehensive understanding of the light chemical equipment system, so as to improve the practical ability of students.

But in the long run, in order to improve the students' ability of analysis and design, the teaching plan should be adjusted, to enhance course learning on the mechanical, such as engineering mechanics and material mechanics, measurement and interchangeability theory, materials processing technology courses, so that the students are not only longer than the development of technology research, but also has a better practical ability in the equipment design and transformation, on-site production .

\section{Diversified the Way of Teaching and Cultivate Innovative Thinking}

In the teaching of this course, we have adopted the methods of classroom instruction and multimedia teaching. In the questionnaire of student feedback, shows that this approach is relatively easy to accept, but there are also some problems. 
First of all, the content of this course is highly professional. Many students feel the learning process is more boring because they had no direct contact with the equipment and they can not produce intuitive contact with the equipment during learning. And students are prone to emotional difficulties because the light chemical engineering involved in a wide range and a wide range of equipments. So it is easy to lead to poor teaching effect. Secondly, due to the course is arranged in the first semester of the senior year, some students will have the entrance examination, and the other students will find a job. Therefore, if the course content and teaching methods can not effectively attract students, the quality of teaching will be difficult to guarantee.

Therefore, in this case, I emphasize the effective use of multimedia technology and take teaching methods to achieve a flexible and diverse. In the structure of the equipment is usually used to indicate and marked the name of each part to replace the traditional text description. In the explanation of working principle, I often use the Flash or AVI animation form, so that students can visually see them into and out of the routes of the material, the form of processing and material changes. And equipped with the sound of the scene of the device, really do a sound and frame. After the work principle is finished, I will show the real picture of the device in slide, including the pictures when the device is not installed, and the pictures that are running at the job. So that students can have a real sense of the working condition of the equipment. After the above content explained, I will also show a piece of the scene of the video of the equipment when working on , with Chinese or English interpretation, so that students get a direct image of perceptual knowledge, received a multiplier effect of teaching.

In addition, the professional scientific research work is a close combination of theory and practice. Scientific research results often reflect the latest academic developments in related fields. Some research results may reflect the leading academic level at home and abroad. Therefore, taking the scientific research results to enrich the theoretical teaching continuously, not only can deep the students understanding of some theoretical issues, but also can expand the students' academic vision and ideas to improve students' ability to analyze and solve practical problems[3][4].

Based on the above understanding, I have done a lot of works about enriching teaching with scientific researches. For the typical significance of the scientific research achievements of this subject, well-known experts and scholars lecture materials, the professional and related professional doctoral dissertation, I made a system finishing with simple text materials, pictures, slides, film and other forms. I have a number of the subject of the professional research as a topic, collected and compiled a wealth of practical research materials, and combined the teaching content of the course to introduce to the students. In this way, the teaching effect of the course has been greatly enriched, and the students' understanding of the academic frontier has been deepened. And it has laid a good foundation for engaging in professional research work in the future.

\section{Strengthen the Teaching Effect, Continuous Reform and Explore Teaching Methods}

In the teaching process, the teaching effect is directly determined by the students' understanding of the learning content and the degree of knowledge. In order to improve and enrich the teaching methods and teaching content, I designed a questionnaire survey, including the attitude of students to learn, the evaluation of the content, the comments and suggestions of teaching methods and so on. After more than a month of teaching, I have a anonymous survey of students in order to rectify and reform the problems reflected in this survey timely.

From the survey results, the vast majority of students have a positive evaluation of the content and teaching methods. They think that the courseware is accurate and precise and the course of teaching has large amount of information. They have more harvest by learning. But it also reflects some problems, such as a small number of students think classroom teaching slightly faster, some professional terms are not easy to understand, and so on.

For the problem reflected by students, I have summarized the views, showed the vast majority of students are mainly interested in whether teaching content can help and Enlightenment themselves in the future work and development. This reflects that the students show their greatest concern for their own vital interests and employment. Therefore, in the teaching content, I will focus on the 
actual situation of the factory and the equipment problems that the students will be able to meet after concluded. On the way of teaching, we should highlight the combination of animation, picture and video, and reduce the overlap of the existing text information. The effect is quite satisfactory, it not only greatly improve the teaching effect of this course, but also enliven the teaching atmosphere and enhance the students' interest in learning. In addition, it also deeps the students' understanding of the profession. Finally, I recognize the teaching content, explain the the terminology of some mechanical aspects, slightly slow down teaching speed and pay attention to students' understanding and mastery. So students in the classroom can really gain a lot of knowledge.

Through the teaching practice of "light chemical equipment", I think that curriculum construction will be a very important part. For it has close connection with how to improve the actual level of students' basic theory and basic skills, students' innovative spirit and practical ability. So it is necessary to carry out further research and practice on the compilation of teaching materials, teaching contents and teaching methods with the guidance of teaching effect. In the curriculum construction practice of "light chemical equipment", I deeply understand that construct and reform curriculum in many aspects, not only can promote the improvement of the overall level of the curriculum, but also help to improve the teaching level of teachers.

\section{Acknowledgements}

This work was financially supported by the key projects of teaching reform in Qingdao University of Science \& Technology.

\section{References}

[1] J.Q. Zhang: Educational research, (2001) No.10, p.46 (In Chinese)

[2] The Ministry of education. Some opinions on strengthening the teaching of the course of higher education to improve the quality of Teaching [R]. Higher Education (2001) No. 4(In Chinese)

[3] L. Zheng; L. Li; X.P. Yu: computer education , (2006) No.2, p.12 (In Chinese)

[4] Lu Ping, Dong Yuping: Journal of Shandong University of Technology (SOCIAL SCIENCE EDITION), (1997) No.4 p.95 (In Chinese)

[5] Y.W. Wang; L. Chen: Guangdong chemical engineering, (2006) No.1, p.45 (In Chinese)

[6] H.Zhang: Higher Education of Chemical Engineering, Vol.28 (2011) No1, p.89-91(In Chinese)

[7] J.Q. Wu,C.L. Zhao and X. Xu: Chinese audio-visual education, (2000)No6,p.12-13(In Chinese)

[8] H.Zhang: Hubei paper, (2010) No1,p.44-46(In Chinese)

[9] X.B. Han, W.S.Ge, Q. Zhou, et al: Chinese audio-visual education, (2014)No1, p.61-68(In Chinese)

[10]F. Gao: open education research, Vol.18 (2012)No1, p.106-113(In Chinese)

[11]L.G. Zhang and X.L. Liu: E-education research, (2010)No12, p.36-41(In Chinese) 